\title{
ENTREVISTA
}

\section{¿Por qué una tesis sobre la muerte? Entrevista con Txabi Arnal Gil}

Isabel Olid Báez

Universitat Autònoma de Barcelona, Barcelona, Spain

Txabi Arnal Gil es escritor y profesor de literatura en Escuela Universitaria de Magisterio de Vitoria-Gasteiz, Universidad del País Vasco-Euskal Herriko Unibertsitatea. Es conocido por sus obras de literatura infantil y juvenil, por las que ha recibido varios premios. En esta entrevista nos habla de su tesis doctoral, El tratamiento de la muerte en el álbum infantil. Obras publicadas en castellano (1980-2008), escrita dentro del marco del Programa de Doctorado "Psicodidáctica de la Educación y Didácticas Específicas" del Departamento de Didáctica de la Lengua y de la Literatura de la Universidad del País Vasco / Euskal Herriko Unibertsitatea, que versa sobre el tratamiento que dan a la muerte los libros dirigidos a los niños.

ENTREVISTADORA: ¿Por qué una tesis sobre la muerte?

ARNAL GIL: Cuando decidimos embarcarnos en una investigación de esta envergadura, buscamos un tema que resultara innovador, poco estudiado, que nos diera la oportunidad de aportar. En mi labor como profesor universitario imparto clases de literatura infantil, ése es mi ámbito de conocimiento. Además, de vez en cuando, escribo y, de cuando en vez, publico. Soy un apasionado de la literatura infantil y, como tal, siempre me ha llamado la atención el hecho de que, al contrario de lo que sucede con la literatura infantil clásica o tradicional, la literatura infantil actual apenas presta atención al tema de la muerte. Todo es éxito y alegría. Hay poco lugar para la tristeza. Pero la vida también es muerte, y la muerte, a pesar de la honda carga de tristeza que conlleva, no deja de ser algo natural, inevitable y universal. Por otro lado, más allá del tema que

Texto recibido el 3 de febrero de 2013, aceptado el 10 de febrero de 2013, versión final recibido el 12 de febrero de 2013 
tratan, que no es otro sino el de la muerte, siempre he tenido entre mis favoritos Regaliz de Sylvia Van Ommen, y ¿Cómo es posible?! De Peter Schössow. Dichos álbumes fueros los primeros que analizamos en nuestro estudio. Posteriormente buscamos otras obras infantiles que trataran este tema. Encontramos un total de 57, un corpus suficiente como para adentrarnos definitivamente en el estudio de la manera en que la literatura infantil actual aborda el "incómodo" tema de la muerte.

ENTREVISTADORA: ¿Por qué crees que es bueno que los niños piensen en la muerte?

ARNAL GIL: La muerte es un tema enormemente atractivo tanto para niños como adultos. Es triste, pero, tal y como antes indicaba, también universal e ineludible. Entonces, ¿por qué ocultarlo a los ojos de la infancia? La muerte está por todas partes. Incluso puede decirse que es preciso hacer un esfuerzo para no abordarla. Es por ello que se hace necesaria una literatura infantil que, alejada de las interferencias del didactismo, ayude en el afrontamiento del fracaso, la pérdida, el sufrimiento y la finitud (la propia y la de los seres queridos), y se aleje de las contaminaciones ideológicas y también de la mentira.

ENTREVISTADORA: Hay quien critica el uso de la literatura infantil para hacer llegar a los niños un mensaje excesivamente didáctico. ¿Dónde te sitúas en este debate?

ARNAL GIL: Hay muchos libros disfrazados de literatura infantil que no son sino textos meramente didácticos. Y no podemos negar que cumplen una función, pero, ¡ojo!, no son literatura. ¿Dónde me sitúo? ¿Dónde los sitúo? Desde luego, fuera del ámbito de la literatura. Los respeto, pero como escritor y profesor de literatura infantil, no me interesan.

ENTREVISTADORA: Has analizado álbumes de varios países. ¿Has encontrado diferencias sustanciales en la forma de contar la muerte a los niños en función del lugar donde se escriben, o hay otros factores que afecten más sustancialmente la variedad de enfoques? 
ARNAL GIL: Hemos analizado álbumes publicados en castellano desde 1980 hasta 2008, álbumes que todavía están vivos, fáciles de hallar en nuestras tiendas y bibliotecas. La mayoría, hasta en un $79 \%$, son traducciones, sobre todo procedentes de Europa Occidental. La producción estatal es escasa y muy dependiente del exterior. Es más, se publica mayor número de obras de esta índole en catalán que en castellano. Con estos datos en la mano, no podemos pensar más que en un enfoque europeocentrista, la muerte vista desde una perspectiva occidental, donde ésta se presenta como parte ineludible y consecuencia natural de la vida

ENTREVISTADORA: En una sociedad en la conviven varias culturas y formas de educar, ¿cuál crees que debe ser el papel de la escuela pública en el tratamiento de temas tabú como la muerte?

ARNAL GIL: Los temas tabú no existen, al ignorarlos nosotros los convertimos en "innombrables". La muerte debe encontrar su espacio en el curriculum escolar. Hablamos a nuestros niños y niñas de la vida, del nacimiento, de la reproducción, incluso de la madurez... pero la muerte no aparece por ningún lado. No lo entiendo. Debería ser tratada de manera laica, alejada de contaminaciones ideológicas. Antes decía que la muerte está por todas partes. Muchos niños y niñas han vivido, o pronto vivirán, alguna experiencia con la muerte (animales, abuelos, vecinos...), y, sin embargo... Vivimos en la sociedad del éxito, y la muerte es entendida como fracaso. Por ello resulta arrinconada.

ENTREVISTADORA: ¿Crees los maestros están preparados para abordar el debate que puede generar en clase?

ARNAL GIL: No, nos faltan herramientas. No sabemos qué hacer con la muerte, no sabemos cómo tratarla, por eso la ignoramos. Esperamos que nuestra tesis pueda dar un poco de luz a tanto oscurantismo.

ENTREVISTADORA: En los cuentos estudiados, ¿en qué medida se trata la posibilidad de la vida más allá de la muerte? 
ARNAL GIL: El "más allá" o el "después" se mueve en el terreno de lo abstracto, de las especulaciones, las creencias, los deseos y lo indemostrable, características que lo sitúan muy lejos de la incipiente capacidad de abstracción del público al que van dirigidos preferentemente los álbumes infantiles. Pienso que todo ello condiciona el alto porcentaje de obras (59.65\%) que no le dedica mención alguna. Sin embargo, no debemos pasar por alto la significatividad del porcentaje complementario a aquél que acabamos de señalar. Es decir, disponer de un $40.35 \%$ de álbumes que ofrecen parte de su atención al "más allá", al "después", y a la esperanza o a la creencia de que la muerte no implica el final de la existencia, nos conduce a pensar en la gran importancia que para el autor, enraizado en su sociedad y cultura, tiene el mostrar una opción, tal vez un deseo, de continuidad de la vida tras la muerte.

ENTREVISTADORA: Afirmas que en muchas ocasiones los autores eluden la palabra "muerte". ¿Qué lugar crees que debe tener cuando hablamos con los niños sobre el tema?

ARNAL GIL: Es cierto que los giros y recursos literarios utilizados para aludir de manera indirecta a la muerte resultan variados. No existe una metáfora, imagen literaria, giro o eufemismo que el autor use preferentemente con tal función. Acciones relacionadas con el abandono de lugar en el que habitualmente transcurría la vida del difunto (viaje), verbos que hacen referencia a su ausencia (no estar, irse), alusiones al cese de la actividad vital (parar, dejar, dormir), y giros coloquiales y humorísticos (estirar la pata), sirven tanto para referirse a la muerte, como para sugerir sensaciones estrechamente relacionadas con ella. Sin embargo, no creo que debamos pensar en estos giros como un tabú dentro del tabú. Al contrario. No olvidemos que estamos hablando de literatura, y en éste, como en cualquier otro ámbito del arte, debe primar la libertad creadora del artista. Él o ella escriben y, por lo tanto, deciden de qué manera desean narrar su historia. Diferente es el día a día, nuestro trato cotidiano con niñas y niños, a quienes debemos hablar con todo el cariño del mundo pero sin enmascarar la realidad. La muerte es muerte y todo lo demás... dejémoslo en riqueza de lenguaje. 
ENTREVISTADORA: Parece que España va a la cola en la producción de álbumes menos convencionales. Como teórico pero también como escritor, ¿a qué crees que se debe?

ARNAL GIL: ¡Ay, España! Bueno... cómo decirlo... mucho fútbol poca cultura. En España parece que se tiene muy claro lo que es apto para niños y niñas y lo que no. Y, por desgracia, muchas obras atrevidas, tanto por su estética como por el tema que tratan, son catalogadas como no aptas. Como escritor, si hablas en tu obra de muerte, de homosexualidad, de explotación, racismo... no resulta raro encontrarte con comentarios del tipo: "nos gusta tu obra, la creemos necesaria, pero tomando en consideración que son los padres quienes compran los libros de sus hijos, y acostumbran a rechazar temas incómodos... solo resta decir que, ante el mismo gasto de edición, y dado que tenemos que comer, preferimos optar por obras más comerciales."

ENTREVISTADORA: ¿Has encontrado álbumes que traten sobre la muerte en situaciones de injusticia social (hambruna, guerra, crisis)?

ARNAL GIL: Sí, hay álbumes que tratan la muerte violenta dese una perspectiva histórica. Te daré dos ejemplos: Rosa Blanca de R. Innocenti y Humo de A. Fortés. Ambos hablan del genocidio judío, y también gitano en el segundo caso, durante la Segunda Guerra Mundial. Son obras duras, pero también hermosas.

ENTREVISTADORA: Entre las conclusiones de tu tesis, señalas la notable audacia por parte del álbum al atreverse a abordar aspectos muy delicados relacionados con el fin de la vida. ¿A qué aspectos te refieres?

ARNAL GIL: Me refiero a que, aunque con porcentajes bajos (no suelen alcanzar el 10\%) contamos con obras que se atreven a otorgar a la muerte un sentido y una finalidad positiva, que no es otra sino liberar al enfermo del enorme padecimiento que le provoca su enfermedad. Decía que son pocas las obras que enfocan la muerte desde esta perspectiva, sin embargo, debemos valorar muy positivamente la valentía por parte del 
álbum infantil, al tratar respetuosamente un tema delicadísimo y de gran peso cualitativo, ya que además de aceptar el reto de mostrar la muerte sin tapujos al niño y a la niña, no niega la posibilidad de que en algún momento se llegue a desear la propia muerte o, en su caso, la de un ser querido. Además, el álbum tampoco niega la posibilidad de que se muestre feliz quien sabe que va a morir, sentimiento producto de estar rodeado por sus seres más queridos durante sus últimos momentos.

ENTREVISTADORA: ¿Se podría pensar que los álbumes analizados en tu tesis muestran un panorama oscuro y deprimente?

ARNAL GIL: Para nada. Al proceso de duelo se le presta un gran espacio, y en la mayoría de las obras este proceso se resuelve de manera satisfactoria, con el renacimiento de la alegría y de las ganas de vivir, trasmitiendo de esta manera un mensaje optimista y desmitificador.

ENTREVISTADORA: Indiscutiblemente, la muerte es un tema de amplia repercusión emocional y afectiva. Teniendo en cuenta que estas facetas del ser humano suelen recaer fundamental y tradicionalmente en las mujeres, ¿has observado un equilibrado tratamiento de género?

ARNAL GIL: Sí, lo he observado y me ha sorprendido muy gratamente. Parece como si el autor, una vez se ha metido en un terreno innovador, quisiera hacer las cosas de la mejor manera posible. Así, la niña protagonista no es para nada una exigua minoría, fundamentalmente secundaria, y comparte junto al niño espacios y actitudes que le permiten disfrutar del conjunto de sus potencialidades, entre las que, por supuesto, se encuentran la emotividad, la autoconfianza, y la sensibilidad. Es indudable la importancia que en esta labor co-educativa tiene la franja de edad a la que los álbumes infantiles están preferentemente dirigidos, una etapa en la que el niño y la niña, en buena medida, todavía se encuentran a salvo de contaminaciones y estereotipos sexistas. Si analizamos el tratamiento que, desde la perspectiva de género, recibe la expresión de los sentimientos por parte de los y de las dolientes, cabe afirmar que ni en el reparto de roles, ni tampoco en la relación entre el sexo del protagonista doliente y el tipo de 
sentimiento por éste expresado, se aprecia tendencia sexista alguna. Los números correspondientes a la participación de niños y niñas en la manifestación de sentimientos consecuencia de la pérdida de un ser querido son bastante similares (44.89\% para los niños y $36.73 \%$ para las niñas), incluso levemente superiores para los primeros, situación novedosa por tratarse de un campo tradicionalmente reservado casi en exclusividad al género femenino. En cuanto al número de dolientes adultos masculinos que hacen explícitos sus sentimientos, también nos encontramos con que éstos superan, ahora notablemente, al número de dolientes adultos femeninos: $71.42 \%$ contra $28.57 \%$. De esta manera, el corpus objeto de análisis en esta investigación refrenda las tesis de Colomer, cuando, ya hace unos añitos, en un análisis referido a los más significativos títulos infantiles editados entre 1970 y 1994, afirmaba que "los niños también pueden ser los sujetos de temas intimistas, poéticos y de conflictos psicológicos", y que "al igual que sucede con los niños, también puede señalarse una mayor presencia de valores imaginativos, afectivos y humorísticos en las figuras paternas”.

Y todavía hay más. Si atendemos a la relación entre el sexo del protagonista doliente y el tipo de sentimiento expresado por éste, nos encontramos con un nuevo argumento que refuerza la idea de que nos hallamos ante un campo que rompe con la tradicional y hermética separación de actitudes y valores entre sexos. Así, podemos citar como ejemplos más clarificadores de lo anteriormente expuesto que, contrariamente a lo que por tradición se supone que no es un valor femenino, la niña es quien en más oportunidades se rebela contra la muerte de su ser querido, llegando casi a duplicar los números correspondientes a los niños. Por otro lado, la negación de una realidad que no gusta en absoluto, sentimiento muy ligado a la rebeldía, es manifestada a través de las niñas en el doble de ocasiones en que es el niño quien hace lo propio. Y no se vayan que todavía hay más. El miedo, emoción "inapropiada" en pocas ocasiones vinculada al sexo masculino, es expresado por el niño en el triple de ocasiones en que lo hace la niña.

En definitiva, y recurro nuevamente a una cita, tal y como anunciaba Orquín en 1989 para el conjunto de la literatura infantil posterior a la década de los 70, el álbum cuyo argumento gira en torno a la muerte reivindica "la expresión de la afectividad para ambos sexos y el desarrollo armónico de la personalidad propia sin que ésta esté prefijada por el sexo con el que se nace". Y añadimos nosotros, y recurrimos para ello a 
una tercera cita de Barragán Medero, que los álbumes analizados dan un importante paso hacia adelante en "la asunción profunda de un nuevo modelo de mujer que implica una redefinición del estereotipo sobre lo femenino y lo masculino". El hombre por su parte, "comenzaría a librarse de la propia maraña que él mismo ha creado, y que le obliga a negarse a sí mismo.” ¡Casi nada!

ENTREVISTADORA: Vamos terminando. Hemos hablado de diversos aspectos en los que el álbum infantil que aborda el tema de la muerte se muestra valiente e innovador. De cualquier manera, imaginamos que habrá otros aspectos muy poco o nada tratados, y que será necesario desarrollar en un futuro para seguir caminando en dirección hacia la desmitificación y naturalización de este tema.

ARNAL GIL: En efecto, existen diversos aspectos, hechos y realidades relacionados con la muerte, hoy día nada o muy poco tratados por el álbum infantil. Por ejemplo, es característica extendida entre los álbumes analizados, mostrar la cara más suave de la muerte, la menos trágica, el final natural del ciclo de la vida. Las enfermedades irreversibles, el suicidio y la eutanasia están práctica o totalmente desterradas de esta parcela de la literatura. La enfermedad, por su parte, es concretada en muy pocas ocasiones. La descripción del cadáver y de los efectos físicos causados por la enfermedad o por el paso del tiempo, se presentan también como aspectos de incómodo tratamiento. Y también la despedida. Se dedica muy poco espacio a un aspecto que, en opinión de Worder, es básico para culminar con éxito el proceso de duelo.

ENTREVISTADORA: Queda mucho por hacer...

ARNAL GIL: Queda mucho por hacer. Todo parece indicar que se están dando los primeros pasos hacia la superación de una cuestión que todavía dista de ser tratada con total normalidad y naturalidad. Así, estableciendo una comparativa entre la producción de las tres últimas décadas, se advierte que nunca en la literatura infantil actual, ni en el álbum en particular, la muerte había tenido la presencia que ahora tiene. Sin embargo, una duda muy razonable nos asalta: queda por demostrar si este significativo aumento de títulos responde a una demanda social, educativa, escolar y editorial coyuntural, o si 
es producto de la libertad creativa de los autores y de las autoras. Que la tendencia a ir acabando con la marginación con que es tratada la muerte se consolide, o que, por el contrario, únicamente revele la expresión de una moda o de un interés pasajero, es algo que se deberá en el futuro.

Y también queda investigar sobre literatura infantil y racismo, miedos, discapacidades, soledad, homosexualidad, abuso, marginación...

ENTREVISTADORA: Muchas gracias por su tiempo.

\section{Referencias de la entrevistadora:}

Isabel Olid Báez (Mataró, 1977) traduce, ejerce de docente y escribe novelas, ensayos, poesías, cuentos, blogs y textos de índole diversa. Entre su producción destaca el ensayo Herö̈nes postmodernes: models literaris contra l'universal masculí (premio Rovelló 2010), el cuento ¡Estela, grita muy fuerte! (premio Qwerty al mejor libro infantil 2009), la novela Una terra solitària (premio Documenta 2010) y el libro de cuentos La mala reputació (premio Roc Boronat 2012). También colabora en diferentes medios de comunicación.

Email: Isabel.olid@uab.cat

\section{Para citar este artículo}

Olid Báez, I. (2013). ¿Por qué una tesis sobre la muerte? Entrevista con Txabi Arnal Gil. Bellaterra

Journal of Teaching \& Learning Language \& Literature, 6(1), 72-80. 